\title{
Corpos Trans* na Medida Socioeducativa de Internação: Desestabilizando Práticas e Produzindo Novidades
}

\author{
Aline Monteiro Garcia ${ }^{1}$ \\ ${ }^{1}$ Universidade Estácio de Sá, RJ, Brasil.
}

\author{
Luisa Bertrami D’Angelo ${ }^{2}$ \\ ${ }^{2}$ Universidade do Estado do Rio de Janeiro, RJ, Brasil.
}

\begin{abstract}
Resumo: O presente trabalho discute como a chegada de uma jovem trans* em uma unidade feminina de internação do Departamento Geral de Ações Socioeducativas (Degase-RJ) movimentou, produziu tensões e revelou importantes dinâmicas, práticas e discursos a respeito de gênero, sexualidade, transexualidade e direitos. Tomando como acontecimento a chegada de dessa jovem, a qual chamaremos de Estrela, procuramos identificar as forças que possibilitam e/ou dificultam a discussão de gênero no sistema socioeducativo, bem como os modos como o corpo de Estrela produz movimentos instituintes que desestabilizam certezas e verdades a respeito do gênero, do sexo e do desejo. O trabalho se desenvolveu a partir de duas pesquisas realizadas na referida unidade, ambas pautadas pelo paradigma ético/estético/político da cartografia. Buscando acompanhar alguns processos desenrolados a partir da chegada de Estrela, como a criação de um Grupo de Trabalho sobre diversidade sexual e de gênero e a produção do Regimento Interno do Degase (Decreto n. 46.525/18), discutimos como a presença da jovem demandou a criação de ações e estratégias institucionais que, não sem dificuldades e desafios, buscaram pautar a temática de gênero a partir de uma perspectiva da garantia de direitos.
\end{abstract}

Palavras-chave: Sistema Socioeducativo, Gênero, Transexualidade, Adolescentes.

\section{Trans* Bodies in the Juvenile Detention Centers: Destabilizing Practices and Producing Novelties}

\begin{abstract}
This article debates how the arrival of a young transexual woman in a female juvenile detention center (Degase) in Rio de Janeiro tensioned and revealed important dynamics, practices and discourses about gender, sexuality, transexuality and rights. Taking Estrela's arrival as a starting point, we aim to identify the forces that produce and/or make difficult some discussions about gender in this context, as well as to debate the ways Estrela's body made unstable some certainties about gender, sex and desire. The discussions here come from two different researches developed in the female juvenile detention center where Estrela was, both using the cartographic method and its ethical/aesthetic/political paradigm. In order to follow some processes unrolled by Estrela's arrival, such as the creation of a group to discuss gender and sexual diversity and Degase's internal regiment, we discuss how Estrela's presence demanded actions and strategies to talk about gender from a human right's perspective, although not without difficulties and challenges.
\end{abstract}

Keywords: Juvenile Detention Centers, Gender, Transexuality, Adolescents. 


\title{
Los Cuerpos Trans* en Centros de Encarcelamiento Juvenil: Prácticas Desestabilizadoras y Producción de Novedades
}

\begin{abstract}
Resumen: El presente trabajo discute cómo la llegada de una joven trans* en una unidad femenina de internación del Departamento General de Acciones Socioeducativas (Degase-RJ) movió, produjo tensiones y reveló importantes dinámicas, prácticas y discursos acerca de género, sexualidad, transexualidad y derechos. Tomando como acontecimiento la llegada de esa joven, a la que llamaremos Estrela, buscamos identificar las fuerzas que posibilitan y/o dificultan la discusión de género en el sistema socioeducativo, así como los modos como el cuerpo de Estrela produce movimientos instituyentes que desestabilizan certezas y verdades sobre género, sexo y deseo. El trabajo se desarrolló a partir de dos investigaciones realizadas en la referida unidad, ambas pautadas por el paradigma ético/estético/político de la cartografía. Buscando acompañar algunos procesos desenrollados a partir de la llegada de Estrela, como la creación de un Grupo de Trabajo sobre diversidad sexual y de género y la producción del Reglamento Interno del Degase, discutimos cómo la presencia de la joven demandó la creación de acciones y estrategias institucionales que, no sin dificultades y desafíos, buscaron pautar la temática de género desde una perspectiva de la garantía de derechos.
\end{abstract}

Palabras clave: Sistema Socioeducativo, Género, Transexualidad, Adolescentes.

\section{Introdução}

Os últimos anos colocaram em pauta a diversidade sexual, com destaque para as questões trans*1, que ganharam visibilidade nas Paradas do Orgulho LGBT ${ }^{2}$ e nas denúncias de violência contra travestis e transexuais e que, atualmente, encontram-se no centro de importantes disputas políticas local e nacionalmente. A intersecção desta discussão com o marcador geração, no entanto, ainda aponta para lacunas e silenciamentos. Acrescendo a esta trama a socioeducação, esse emaranhado se complexifica e, ao mesmo tempo, é possível observar ainda mais como a intersecção entre gênero, sexualidade, geração e privação de liberdade levanta importantes questões a serem desdobradas pelos estudos de gênero, da transexualidade e da privação de liberdade.

O Estatuto da Criança e do Adolescente - ECA (Lei No 8.069, 1990), norteado pela Doutrina da Proteção Integral, compreende crianças e adolescentes como sujeitos de direitos; porém, ainda há muito o que se avançar na efetivação das garantias previstas neste importante dispositivo legal. Apesar do que constatam Silva, Sereno e Gonçalves (2014) acerca do processo que vem dando lugar ao termo adolescente no lugar da concepção de menor, diferenciação esta fundamental para a discussão acerca de geração e privação de liberdade desde uma perspectiva da garantia de direitos, há ainda uma concepção hegemônica da adolescência como campo natural da crise, e a sexualidade aparece então como fator de preocupação que demanda vigilância e controle. Conforme mencionaram D'Angelo e Garay Hernández (2017) a respeito de uma pesquisa realizada no sistema socioeducativo do Rio de Janeiro:

O uso recorrente da expressão o adolescente denota que o termo parece servir para classificar não somente um sujeito, mas um grupo de jovens, homens ou mulheres. O adolescente, assim, torna-se uma figura homogênea, uniforme, quase como um monstro que, conforme falou um agente socioeducativo, "[...] acha que pode tudo, que é contestador, rebelde, que quer

\footnotetext{
${ }^{1}$ Atualmente, o termo transgênero caiu em desuso, e a nomenclatura corrente é trans*. Os movimentos sociais que lutam pela visibilidade das pessoas trans* utilizam o asterisco acompanhando a palavra trans* para designar um termo guarda-chuva, que engloba diferentes identidades, podendo incluir pessoas trans* que se identificam dentro ou fora do sistema normativo binário de gênero (masculino x feminino). Consultado em: https://transfeminismo.com/trans-umbrella-term/.

${ }^{2}$ A sigla se refere a Lésbicas, Gays, Bissexuais, Travestis e Transexuais. "Em alguns locais no Brasil, o T [...] também diz respeito a transgêneros, ou seja, pessoas cuja identidade de gênero não se alinha de modo contínuo ao sexo que foi designado no nascimento” (Facchini, 2011, p. 10).
} 
mostrar que existe, que resiste". "Cheio de hormônios", "impulsivo", "raivoso" foram outros adjetivos usados por profissionais, além de "desequilibrada", "inconsequente" e "com os nervos à flor da pele", adjetivos que, associados às jovens mulheres, parecem ser evocados de modo a traduzir uma certa instabilidade do feminino a qual, quando atravessada pela geração, aparece de modo exacerbado (p. 7).

Em seu artigo 15, o ECA afirma que "a criança e o adolescente têm direito à liberdade, ao respeito e à dignidade como pessoas humanas em processo de desenvolvimento e como sujeitos de direitos civis, humanos e sociais garantidos na constituição e nas leis". No entanto, quando se trata de adolescentes em cumprimento de medida socioeducativa de internação, a visão que se tem da adolescência como campo problemático torna-se agravada, dificultando a garantia de seus direitos.

Em um contexto de encarceramento em massa no qual cada vez mais jovens, em especial negros(as) e pobres, são transformados(as) em alvos preferenciais das tramas punitivistas que capturam determinados sujeitos e grupos no contexto do sistema de justiça, a chegada de adolescentes travestis e transexuais vem movimentando o cotidiano das unidades socioeducativas, que historicamente organizam a distribuição dos(as) adolescentes com base no sexo designado no nascimento e cujas práticas cotidianas são orientadas e articuladas por processos generificadores e generificados.

No Rio de Janeiro já existem regulamentações quanto ao tratamento destinado às pessoas trans* nas penitenciárias, como a Resolução no 558/2015 do Secretaria de Estado de Administração Penitenciária $\left(\right.$ SEAP-RJ) ${ }^{3}$. No âmbito do sistema socioeducativo, ainda que não haja resolução similar, foi publicado, ao final de 2018, o Regimento Interno do Departamento Geral de Ações Socioeducativas do Rio de Janeiro (Degase-RJ), organização responsável pela execução das medidas de internação e semiliberdade, no qual consta uma seção que trata especificamente do atendimento ao público LGBT. Esse novo instituído foi fruto de um longo processo de trabalho e discussão, o qual analisaremos ainda neste trabalho.

Tomaremos como ponto de partida e acontecimento analisador a chegada e presença de uma jovem trans*, internada inicialmente numa unidade masculina e depois transferida para a única unidade feminina de internação do estado. As situações e discussões aqui presentes são resultados da articulação de duas pesquisas realizadas no âmbito do Degase, sendo uma pesquisa de doutorado e uma pesquisa interinstitucional sobre sexualidade e juventude. Em ambas as pesquisas, a cartografia foi método, procedimento e postura ético-política fundamental para acompanhar os processos, disputas, tensões e produções de subjetivações que (se) formaram (n)os campos de pesquisa.

\section{Estrela chega ao Degase}

Estrela foi protagonista de um acontecimento inédito no Degase: foi a primeira jovem transexual formalmente reconhecida como tal pelo sistema de justiça fluminense a cumprir medida de internação em uma unidade feminina no estado - ainda que sua ida para a unidade feminina não tenha sido automática, tendo Estrela passado por uma unidade masculina antes que uma determinação judicial implicasse em sua transferência para unidade em conformidade com sua identidade de gênero A presença da jovem, tanto na unidade masculina quanto na feminina, colocou diversas instituições e práticas em análise, bem como provocou movimentos instituintes no sistema.

Aquilo de seu corpo que desestabilizava as fronteiras do gênero borrava, também, normas, regras e processos institucionais, convidando, ou quase exigindo, que os modos de lidar com sua presença reconfigurassem os repertórios das práticas da unidade. Tratava-se de "objeto quente", conforme Latour compreende os acontecimentos que são alvo de disputas e controvérsias (Freire, 2013).

A chegada de Estrela se configurou num potente analisador, aqueles acontecimentos que fazem "surgir, com mais força, uma análise; que faz aparecer, de um só golpe, a instituição ‘invisível’” (Lourau, 1993, p. 35). A partir do método cartográfico, seguimos as

\footnotetext{
${ }^{3}$ A Resolução no 558, de 29 de maio de 2015, da Secretaria de Estado de Administração Penitenciária, estabelece diretrizes e normativas para o tratamento da população LGBT no sistema penitenciário do Rio de Janeiro. Apesar das enormes dificuldades para efetivação das garantias previstas na Resolução, sua existência é um importante dispositivo que pode ser acionado na luta pela garantia de direitos como o uso do nome social e a possibilidade de cumprir pena em estabelecimento penal condizente com a identidade de gênero da pessoa em questão.
} 
linhas e pistas desse acontecimento, já que "o cartógrafo acompanha um processo que, se ele guia, faz tal como o guia de cegos que não determina para onde o cego vai, mas segue também às cegas, tateante, acompanhando um processo que ele também não conhece de antemão" (Passos, \& Eirado, 2014, p. 123).

\section{Adolescentes trans* no Degase: revisitando a história}

Essa não foi a primeira vez que a presença de uma jovem trans* causou reboliços no Degase. Barros e Julião (2015) contam que, em 2008, três adolescentes narradas como sendo do sexo masculino ${ }^{4}$, de orientação e identidade sexual destoante do que é socialmente instituído como norma, foram encaminhadas para uma unidade de internação masculina, tendo como determinante para essa decisão o sexo designado ao nascimento. Em 2013, outra adolescente nas mesmas condições foi encaminhada para outra unidade masculina. Falam dessa última como alguém que apresentava uma "feminilidade inerente", por ter um longo aplique de cabelo. Discutiremos, mais adiante, a naturalização do binarismo de gênero a partir da compreensão que não há nada de inerente à masculinidade e à feminilidade, e sim construções que servem a propósitos políticos e sociais; mas, por enquanto, ficamos com a constatação dos autores de que essas adolescentes se transformaram em atração nas unidades por conta do modo como se apresentavam e dos elementos que utilizavam em seus corpos para a afirmação de suas identidades.

No caso de 2008, os autores afirmam que os profissionais questionaram a permanência delas na unidade e as alojaram na sala da equipe técnica, até que a Direção Geral resolvesse a questão. Analisam que aconteceu com essas adolescentes a reprodução da violência física e simbólica a que estão submetidos os gays, lésbicas, bissexuais, travestis, transexuais e transgêneros em nossa sociedade, como mostram os relatórios sobre Violência Homofóbica no Brasil (2011; 2012, apud Barros, \& Julião, 2015). Sobre as experiências de violência heterossexistas vividas por pessoas trans* e travestis na intersecção entre gênero e o Estado, Salo de Carvalho (2012) aponta que:
Este complexo processo de legitimação da violência heterossexista poderia ser decomposto em três níveis fundacionais que configuram as culturas heteromoralizadoras e heteronormalizadoras: o primeiro, da violência simbólica (cultura homofóbica), a partir da construção social de discursos de inferiorização da diversidade sexual e de orientação de gênero; o segundo, da violência das instituições (homofobia de Estado), com a criminalização e a patologização das identidades não-heterossexuais; o terceiro, da violência interpessoal (homofobia individual), no qual a tentativa de anulação da diversidade ocorre através de atos brutos de violência (violência real) (p. 154).

Barros e Julião (2015) relatam que havia desconforto dos servidores e dos outros jovens em relação ao modo como aquelas identidades de gênero eram expressadas. Colocam que os adolescentes olhavam ora com curiosidade, ora, com desprezo e ódio. Analisam, ainda, que tais comportamentos se pautam em valores heteronormativos, que produzem a dificuldade em aceitar o convívio com pessoas cujos corpos e experiências encontram-se à margem desse padrão.

Segundo os autores, alguns profissionais questionaram se o lugar para essas adolescentes seria a unidade feminina. Os autores problematizam essa solução e, sem negar que este seria um lugar possível, pontuam que na unidade feminina também poderia haver rejeição por parte de outras jovens e de profissionais. É interessante pensar no jogo entre o que é "possível" e o que é de direito e como ambos os discursos podem ser operacionalizados e acionados para fins distintos.

Se, por um lado, é pertinente imaginar que estar em uma unidade feminina possa significar uma série de rejeições e violações, por outro é necessário também pensar quando este argumento é acionado institucionalmente como medida que visa embarreirar qualquer tipo de ação ou estratégia que objetive a garantia de direitos de jovens travestis e trans* no sistema socioeducativo. Vale, ainda, questionar o quanto é possível garantir e afirmar direitos num contexto de privação de liberdade que, por excelência e definição, é produtor de inúmeras violências.

\footnotetext{
${ }^{4}$ Os autores definiram como sendo travestis as jovens dos casos analisados, no entanto utilizam o artigo masculino para referir-se a elas. Considerando as discussões produzidas pelos movimentos sociais e pela academia nos dias atuais, hoje entende-se que o uso do artigo masculino para se referir a travestis é considerado agressivo e desrespeitoso, por não reconhecerem esta experiência dentro de um espectro de feminilidades. Buscando contextualizar e problematizar o uso de artigos masculinos para tratar de experiências de travestis e mulheres trans*, usaremos os artigos femininos quando nos referirmos aos três casos citados anteriormente por outros(as) autores(as).
} 
Como desfecho do caso citado por Barros e Julião (2015), a Direção-Geral do Degase foi acionada e realizou uma reunião com alguns assessores e a equipe técnica da unidade feminina. Dentre as questões que emergiram na reunião, foram destacadas "a necessidade de se pensar em procedimentos para estes casos; a ampliação da discussão sobre saúde e diversidade sexual; a capacitação dos servidores para lidar com o tema" (Barros, \& Julião, 2015, p. 123).

A solução a que chegaram foi transferir as adolescentes imediatamente para a unidade feminina; porém, a equipe técnica da referida unidade se mostrou contrária ao encaminhamento, argumentando que, por terem o órgão genital masculino, poderiam se relacionar sexualmente com as adolescentes, engravidando-as. A Direção-Geral acionou o juizado e o juiz resolveu acolher a sugestão de encaminhá-las para uma semiliberdade masculina, considerando que seria o espaço mais adequado para resguardar a segurança das mesmas - justificativa no mínimo descabida, pois na semiliberdade há trânsito dos(as) adolescentes entre dentro e fora da unidade, sendo comum ocorrerem ameaças e conflitos decorrentes de grupos faccionais presentes nos territórios dos Centros de Recursos Integrados de Atendimento ao Adolescente (CRIAAD).

O encaminhamento para CRIAAD também ocorreu em 2015, quando uma decisão da Vara de Infância e Juventude da Capital encaminhou uma adolescente travesti para cumprir a semiliberdade em unidade feminina. Na matéria veiculada na mídia, havia a informação de que o fato fez com que os(as) servidores(as) ficassem inseguros em relação ao local no qual a adolescente dormiria, visto que pairava o medo de que se relacionasse sexualmente com as demais adolescentes (Barros, \& Julião, 2015). Nota-se, portanto, que tanto em 2008 quanto em 2015, o medo de que uma jovem travesti/trans* engravide outras jovens cis é acionado pela instituição frente à presença destes corpos no cotidiano da unidade.

Em relação ao caso citado por Barros e Julião (2015) ocorrido no ano de 2013, diferentemente do que aconteceu em 2008, a equipe de referência ${ }^{5}$ desenvolveu oficinas sobre adolescência e sexualidade em parceria com educadores em saúde do município, nas quais os adolescentes da unidade participaram, inclusive a jovem travesti, possibilitando a reflexão sobre a temática e o preconceito (Barros, \& Julião, 2015). No entanto, nenhum trabalho em nível institucional se deu, até a chegada da Estrela, em 2016.

No ano de 2016, Estrela foi internada numa unidade masculina, diferente daquela onde foram internados os jovens em 2008 e 2013, onde permaneceu por aproximadamente três meses. Sua estadia foi marcada por diversas violações de direitos muito semelhantes ao que aconteceu com as jovens que deram entrada no sistema em 2008 e 2013: ficou em alojamento isolado, posteriormente compartilhando esse espaço com um jovem homossexual; não ia para a escola, pois era hostilizada por outros internos; não fazia cursos, pelo mesmo motivo - afinal, garantir a segurança da jovem era cobrança da qual os agentes não se esquivavam. Ao mesmo tempo em que era hostilizada por uns, era cortejada por outros, tendo tido um namorado que ficou apaixonado por ela, apesar de ser um rapaz fortemente subjetivado pelo machismo e pela homofobia. Estrela já começava, então, a pôr em xeque algumas certezas.

A passagem de Estrela é marcada por estes movimentos de desestabilização que colocam em xeque certezas e verdades sobre o sexo, o desejo e o gênero (D’Angelo, 2017). Sua presença, ao mesmo tempo em que desestabiliza, deixa ver igualmente as forças instituídas que eram também acionadas nos anos anteriores, quando jovens cuja identidade de gênero viam seus corpos atravessarem e serem atravessados caoticamente pelas práticas e discursos do Degase, a começar pelas dúvidas e incômodos dos(as) profissionais:

Na última terça, 11/10, dia de audiência, estava eu e mais 3 técnicas da unidade feminina aguardando as audiências das meninas. Enquanto isso, conversávamos com a gestora das secretarias técnicas, que distribui os adolescentes entre as unidades. $\mathrm{O}$ assunto era transexualidade. $\mathrm{O}$ que fazer com a menina trans? [...]. Ela disse que reuniu "as bichas todas", se referindo tanto aos adolescentes homossexuais quanto à transexual, e perguntou onde preferiam ficar, chegando a perguntar se queriam ir para a unidade feminina, no que eles responderam, segundo ela, que as meninas não os aceitam (Diário de campo, 2016).

${ }^{5}$ Os e as jovens são acompanhados(/s) durante a internação por equipes de referência, mini-equipes, composta por Psicólogas(os), Assistentes Sociais e Pedagogas(os), e cada uma dessas mini-equipes é responsável por um quantitativo de jovens dentro de cada unidade socioeducativa. 
A confusão entre identidade de gênero e orientação sexual se faz presente não só no extrato acima, no qual a funcionária afirma ter reunido "as bichas todas", entendendo que a experiência de Estrela era equivalente àquelas de adolescentes homossexuais, como foi diversas vezes repetida em momentos distintos, em unidades diferentes, por profissionais tanto da equipe técnica, quanto diretores e agentes.

Também a preocupação com a gravidez lança luz sobre esta confusão, evidenciando também a constatação equivocada de que a presença de um pênis no corpo de Estrela significaria, necessariamente, que ela faz uso deste órgão em suas relações sexuais com outras pessoas, ou que seria possível identificar seu desejo hétero ou homossexual baseado em sua identidade e performatividade de gênero. Se, no caso das jovens cis, o sexo é acionado como aquilo que "acalma" a unidade, sendo operacionalizado como moeda de troca (D’Angelo, Garay \& Hernández, 2017) - o que torna possível que jovens que formam casais sejam alocadas em um mesmo alojamento -, no caso de Estrela é exatamente o sexo que não permite, por exemplo, pelo menos no início, que ela divida alojamento com as jovens cis.

A permanência de Estrela na unidade masculina se tornou insustentável, tanto para ela quanto para a equipe e agentes. De fato, a medida socioeducativa estava se resumindo ao aprisionamento, já que nem para a escola a jovem tinha a oportunidade de ir; as reações institucionais ao seu gênero e ao modo como ela o performatizava era fator que agravava as dificuldades de garantir que o cumprimento da medida se desenrolasse conforme as previsões legais. Assim, a equipe técnica trabalhou com Estrela e sua mãe a transferência para a unidade feminina. Ambas entenderam que seria o melhor lugar para o cumprimento da medida. Houve uma articulação entre a equipe técnica da unidade masculina e a Defensoria Pública do Estado do Rio de Janeiro, sendo solicitada uma audiência especial para discutir a transferência. Em fevereiro de 2017, a juíza da Vara de Execuções de Medidas Socioeducativas (VEMSE) determinou, em decisão inédita, que Estrela deveria ir para a unidade feminina. Tal acontecimento possibilita visualizar um jogo de forças que põe em cena continuidades e descontinuidades em relação aos acontecimentos de 2008, 2013, 2015 e 2017.

\section{Estrela na unidade feminina: deslocamentos, potências, tensões e disputas}

A chegada de Estrela impactou significativamente a dinâmica da unidade feminina. Movimentou instituições antes mesmo de ser determinada a transferência. Para alvoroçar mais ainda o Degase, a decisão judicial ordenava que Estrela fosse chamada pelo nome social, e não pelo nome masculino que constava em seu registro civil. Logo de início surgiram argumentos que colocavam em questão a legitimidade da presença de Estrela na unidade feminina:

Algumas falas circulavam inclusive emitindo opiniões pessoais embasadas em argumentos morais, de que não seria certo um 'menino' estar no meio das meninas, que mesmo dizendo que era menina, na verdade era um menino, pois ainda tinha o pênis, que poderia engravidar alguma das outras internas, que poderia utilizar sua 'força de menino' e machucar gravemente as outras internas (Diário de campo, 2017).

Podemos perceber o afeto do medo operando: medo de que machuque as outras internas, medo de que as engravide. Medo e moralidade tecendo uma mesma rede para justificar a não permanência na unidade, empurrando a existência trans* para um não lugar: não cabe na unidade masculina, não cabe na feminina. Mas trata-se de um não lugar que, ao mesmo tempo, é um quase-vários-lugares, porque ela pode e não pode estar nas unidades masculinas e femininas, ao mesmo tempo. Na masculina, ela "pode" porque nasceu homem, mas não pode porque não se adequa ao que se espera do masculino; na feminina, ela pode porque a justiça mandou ou porque ela é uma menina trans*, mas não pode porque ainda tem em si algo que é do masculino. É como se ela tivesse e não tivesse lugar(es) no Degase, ao mesmo tempo, o que torna ainda mais complexa sua experiência e passagem pelo sistema.

As tentativas de explorar a questão da gravidez com a equipe de agentes foram infrutíferas, até que um dia, numa conversa informal e individual com um agente da unidade feminina, o mesmo conseguiu verbalizar que o medo da punição se referia à possibilidade de desconfiarem que foi algum agente que engravidou a adolescente. 
A solução encontrada foi deixar Estrela sozinha em um alojamento, decisão questionada tanto pelos órgãos fiscalizadores quanto por parte da equipe técnica. Quando a questão era levada para Estrela, a mesma relatava a impossibilidade de se relacionar sexualmente com alguma interna, já que não se sentia atraída sexualmente por meninas. No entanto, esse argumento não convencia os profissionais, tendo em vista que a experiência cotidiana da privação de liberdade abre outro campo de possíveis:

$\mathrm{O}$ assunto seguiu para o tema das identidades sexuais, comentando sobre o trânsito que as adolescentes expressam tanto em termos de identidades quanto de orientação sexual. As agentes falam de casos de adolescentes que chegaram aqui vestidas de "Maria" e passaram a ser "João" durante toda a internação ${ }^{6}$. Falaram também das que estavam como 'João' aqui e, ao saírem, estavam vestidas de "Maria". Uma agente contou o caso de uma adolescente que se diz "João", diz que é "macho pra caramba" (sic), mas quando sai pro curso, onde encontra com os meninos, leva a maquiagem e se maquia no banheiro do curso, retirando a maquiagem antes de retornar para a unidade feminina (Diário de campo, restituição, unidade feminina, 2017).

O relato acima fala de uma percepção dos profissionais em relação à sexualidade na privação de liberdade, no caso das meninas, marcada por expressa transitoriedade. Nesse sentido, Estrela poderia realmente se interessar e ter relações sexuais com outras internas. Mas com o passar do tempo, quase todos os óbices iniciais foram se institucionalizando numa convivência mais tranquila, na qual as questões levantadas pelo corpo de Estrela se diluíram:

As agentes ressaltaram o quanto tudo foi difícil com a chegada dela, tanto do lado dos profissionais quanto das adolescentes, mas que agora está tudo bem e ela é só mais uma adolescente, integrada na casa e convivendo com as outras, e que os profissionais também já se acostumaram com a presença dela (Diário de campo, restituição, unidade feminina, 2017).

Por fim, Estrela acabou sendo transferida para um alojamento compartilhado, pois o quantitativo de meninas no estabelecimento não mais permitia que ela ficasse sozinha em um alojamento. Esse foi o argumento que embasou tal mudança, e não a importância do convívio em si. Nesse sentido, assim como no caso dos(as) profissionais, as reações das outras jovens também não foram nem pacíficas, nem unânimes:

As reações foram muitas: as "Joãos" reproduziram preconceitos e discriminações machistas e homofóbicas, chegando a pedir para separar pratos e talheres para Estrela, pois não usariam os mesmos pratos e talheres que ela, mesmo depois de lavados. Curioso notar que isso sempre ocorreu na unidade masculina, mas na feminina nunca percebi isso lá, desde que cheguei. As adolescentes tiveram alguma dificuldade de compreender a questão identitária de Estrela, mas também mostravam abertura para entender; até mesmo os Joãos, que estavam muito incomodados e tendo atitudes discriminatórias. Parece que eles estavam se sentindo ameaçados, afinal, Estrela era uma menina com um "algo a mais". As Marias se mostravam curiosas, querendo conhecer, ver como ela era (Diário de campo, 2017).

A chegada de Estrela causou estranhamento e práticas discriminatórias, principalmente por aqueles adolescentes identificados como João. Estes não a aceitavam na unidade devido à sua identidade de gênero, mesmo sendo notório que Joãos também vivenciem as complexidades relativas à forma como se percebem e se apresentam para o mundo. Indo mais adiante, pairava entre os Joãos um sentimento de disputa desigual, afinal, ela tinha um pênis. Estrela parecia incomodar, e os Joãos, mesmo sendo desviantes da identidade de gênero socialmente atribuída ao seu sexo designado ao nascimento, reproduziram da lógica a instituição heteronormativa ao recepcionarem Estrela.

\footnotetext{
${ }^{6}$ Durante a internação, as adolescentes mobilizam, produzem e vivenciam diferentes performatividades de gênero, que nomeiam de João - aquela(e) que se reconhece como homem ou tem um vulgo masculino e que se expressa no registro de uma masculinidade) e Maria (aquela que evidencia a (se) apresenta (n)o lugar dado ao feminino, como mulher, performatizando matizes de um feminino que pode ser atrelado ao que se chamaria de um feminino "hegemônico".
} 
É curioso notar, ainda, que quando apontado para alguns Joãos a possibilidade de haver alguma proximidade entre as experiências de gênero deles e a de Estrela, eles não identificavam proximidade alguma. Em uma atividade realizada com um grupo de jovens que contava com a presença de um João, ele disse que usar talheres de uma jovem trans* seria o mesmo que "esfregar a escova de dente no ralo e escovar os dentes"; mas, quando perguntado se isso se aplicava também a seus próprios talheres sendo compartilhado com outras jovens, ele prontamente disse que não e que não havia nenhuma semelhança entre ele e uma jovem trans*.

Diante dessa recepção controversa, Estrela reagia. Ela chegou a expressar que tinha a expectativa de ser recebida pacificamente, de certa forma idealizando o convívio com as internas. Talvez porque às mulheres sejam atribuídas as características de dóceis, meigas e pacíficas.

Mas o convívio inicial não foi fácil. Estrela reagia de modo muito agressivo quando vivia alguma situação discriminatória (em especial quando as meninas a chamavam de "viado") e também era provocativa, chegando a irritar severamente quase todas as adolescentes e, por isso, tendo dificuldade em criar um círculo de amizades. Os problemas de Estrela eram praticamente diários, em todos os plantões, e assim foi por pelo menos dois meses. Os agentes e algumas adolescentes discordavam da permanência de Estrela na unidade, sempre justificando pelo fato de ela ainda ter um pênis. Muitas vezes os agentes se mostravam preocupados quando ela se envolvia num conflito, comumente afirmando que ela poderia usar sua "força de menino" e machucar outra interna. Sempre me incomodava esse tipo de afirmação, e eu tentava desconstruir. Afinal, eles estavam baseando o jeito difícil de lidar da Estrela à sua sexualidade, no que eu sempre os lembrava de várias adolescentes difíceis de lidar que já tivemos na unidade, evidenciando que isso não é consequência da sexualidade. Além disso, a questão da "força de menino" eu também tentava desconstruir, afinal, é comum as internas brigarem entre elas e se machucarem sério, com socos no rosto e tudo, chegando até a sangrar e ter que ir ao hospital. Acho que eu fico tão incomodada com essa afirmação porque ela coloca a mulher num lugar de fragilidade, mesmo que as adolescentes diariamente escapem a esse lugar. Além disso, era comum eles dizerem que, se ela veio para a unidade feminina, deveria se comportar como uma menina. Claro que eu sempre os perguntava o que era isso, como é se comportar como uma menina, no que eles chegavam a gaguejar, e dizer que ela não deveria dizer que usaria sua "força de menino" caso houvesse uma briga. Fato é que, do jeito que ela era, realmente deveria falar isso; no entanto, eles reforçavam, expressando receio e fortalecendo esse discurso ameaçador de Estrela. Eu não conseguia enxergar isso como tão real assim, afinal, a compleição física de Estrela não era robusta, pelo contrário; $\mathrm{e}$ tínhamos na casa internas fortes, que quando se envolviam em conflitos, causavam estragos (Diário de campo, 2017).

Reação violenta, à altura da violência sentida, assim como nas ruas, onde trabalhava anteriormente na prostituição. Mas Estrela age enquanto sujeito de direitos, ainda que afirme sua identidade de gênero através do embate, seja com as internas, seja com os(as) agentes. Dizia frequentemente que, se preciso, se utilizaria de sua força "masculina" para defender seu direito. É notório o quanto isso causa preocupação nos profissionais, em especial os agentes homens que, visando garantir a integridade física das outras internas, acabam reforçando a superioridade da força "masculina", e produzindo em Estrela um empoderamento nesse lugar, reafirmado num discurso masculino que reforça o lugar de fragilidade da mulher.

Esse posicionamento se constitui por relações de poder via política identitária, que nos ilude de que os contornos subjetivos são definitivos, essenciais, imutáveis. Um dos efeitos disso, nos diz Foucault (Gallagher, \&Wilson, 1984), é quando a identidade é tomada como regra ética universal, tornando-se o problema mais importante da existência sexual, regendo as relações de modo que seja necessário que tudo esteja de acordo com as identidades. É o que também vemos no caso de Estrela, que ao expressar seu desejo de ser mulher, logo lhe é imposto que se conforme a um lugar de fragilidade, que estaria necessariamente ligado à condição feminina. Se quiser ser mulher, há de ser uma determinada mulher, que responda às demandas do que seria "ser mulher" - demandas essas criadas sobre a ideia de uma sujeita universal, univer- 
salizadora, totalizante, colonialista e sem recorte de raça, classe ou geração: A Mulher. Sobre isso, deve-se levar em consideração que trata-se de um contexto socioinstitucional marcado pelo disciplinamento e adestramento dos sujeitos ali envolvidos, que Foucault (1987) chamou de "docilização dos corpos", que tem por meta a passividade pelo controle dos sujeitos, um modo de exercício de poder que entra em choque com posicionamentos mais ativos e/ou agressivos por parte das adolescentes.

Para além dos desafios que a presença de Estrela colocava no cotidiano da unidade, também o Degase como instituição foi obrigado a operar certas movimentações e deslocamentos. Pela primeira vez no Degase, foi criado um Grupo de Trabalho (GT) para tratar da temática da Diversidade Sexual ${ }^{7}$. Foram convidados representantes do corpo técnico, agentes e direções de todas as unidades, bem como pessoas de fora do Degase que trabalham com essa temática em universidades e pesquisas acadêmicas. No entanto, a participação efetiva iniciou com representantes da unidade feminina; uma técnica da unidade masculina onde Estrela estava internada anteriormente; um agente de outra unidade masculina; uma defensora pública; uma representante da direção geral; dois representantes do Núcleo de Promoção à Saúde do Trabalhador (NUPST); um representante da direção da unidade de semiliberdade feminina e duas pesquisadoras da UERJ.

Diante da baixa representatividade e da importância de discutir com os(as) profissionais que atuam na ponta, a fim de construir as diretrizes de atendimento à Diversidade Sexual, pensamos que o GT deveria circular pelas unidades, dialogando com os(as) profissionais sobre as questões que surgem no cotidiano. Trabalhamos então com a metodologia da roda de conversa, na qual os integrantes do GT se dividiam entre as unidades e procuravam acompanhar os impasses que emergiam nos encontros com os profissionais.

A unidade feminina foi contemplada com a realização de quatro rodas em dias subsequentes, a fim de dialogar com todos os plantões de agentes socioeducativos(as), afinal, foi uma unidade diretamente afetada pela chegada de Estrela. As questões emergiam quase que ao mesmo tempo, todas carregadas de intensidades, ao passo que a maioria delas não era objeto de consenso entre os(as) agentes. Novamente apareceram entendimentos que colocavam identidade de gênero e orientação sexual como uma mesma coisa:

Alguns agentes trouxeram questionamentos acerca do nome social, perguntando por que tinham que chamá-la pelo nome social e por que ela tem que ter um nome social. Sobre o segundo questionamento, dissemos que não há como ter essa resposta, a menos que perguntemos, de modo respeitoso, à própria adolescente. Quanto à obrigatoriedade de ter que chamar pelo nome social, alguns agentes insistem que isso é errado, outros verbalizam que em nada muda na vida deles/as chamá-la pelo nome social, evidenciando divergências e contradições nos modos de pensar e agir dentro do mesmo plantão, contradições essas que pareciam desconhecidas pelo próprio grupo. Conversamos sobre a constituição de identidade e do quanto é importante respeitarmos isso primeiramente, ainda que seja para posteriormente, realizar questionamentos com a adolescente. Quanto à obrigatoriedade, buscam respaldo legal para isso, mostrando desconhecimento dos decretos existentes; alguns chegaram a dizer que só chamariam caso tivesse um dispositivo legal obrigando, no que aproveitamos a oportunidade para trabalharmos com eles os decretos federal e estadual que tratam do uso do nome social (Diário de campo, 2017).

As rodas de conversa se mostraram importantes dispositivos para trazer à tona as questões e tensões relacionadas à temática de gênero, sexualidade e transexualidade. A partir delas, foi possível criar espaços de escuta que permitiram que os(as) próprios(as)

\footnotetext{
${ }^{7}$ Apesar de ser a primeira vez que um grupo de trabalho sobre a temática foi criado, esta não foi a primeira movimentação institucional do Degase para discutir gênero e sexualidade. Barros e Julião (2015) apontam que, em 2008, o Degase fez parceria com uma organização não governamental (ONG) e com a Universidade do Estado do Rio de Janeiro (UERJ) para realizar o primeiro Seminário Socioeducativo com a temática "saúde e diversidade sexual". Nesse evento, estiveram representantes do Ministério Público (MP), Defensoria, Conselho Estadual dos Direitos da Criança e do Adolescente (CEDCA) e Juizado da capital, que reconheceram a importância do debate e a necessidade de efetivação imediata de políticas. Porém, poucos foram os espaços de discussão que se seguiram ao evento e nada se efetivou em termos de diretrizes. Ou seja, seja com maior ou menor capilaridade e capacidade de construção de estratégias e ações, a chegada de jovens trans* ou travestis no Degase forçou, mais de uma vez, um movimento da instituição para se debruçar sobre a temática.
} 
agentes e outros(as) profissionais discutissem os desafios e propostas para lidar com as novidades, os receios e as possibilidades que a presença de Estrela suscitava no cotidiano institucional.

\section{Nome social como analisador: ditos e não ditos na disputa pelo reconhecimento}

O Decreto Estadual no 43.065, de 8 de julho de 2011, e o Decreto Federal no 8.727, de 28 de abril de 2016, dispõem sobre o direito ao uso do nome social nas repartições públicas, entendendo o nome social como o modo como as pessoas travestis e transexuais se identificam e são socialmente reconhecidas. No âmbito do sistema socioeducativo, vale ressaltar que a dificuldade em compreender o nome social como um direito também é direcionada para os Joãos que expressam o desejo de serem chamados pelo nome social escolhido. Os profissionais da unidade feminina onde Estrela cumpria sua medida de internação desconheciam as normativas, mas mesmo com a apresentação dos textos legais nas mencionadas rodas de conversa, os incômodos não cessaram - até porque não estavam reduzidos à ausência ou desconhecimento de normativas sobre o tema.

É possível perceber que a identidade João gera incômodos, em especial quando o jovem marca para o profissional que deseja ser chamada pelo nome social masculino. Alguns profissionais se recusam e, quanto mais se recusam, mais o adolescente afirma essa identidade, num jogo de poder que enuncia a ocupação de um lugar de prestígio, através da força da masculinidade, assim como a afirmação da identidade feminina de Estrela incomoda por não estar em conformidade com o que é esperado para o seu sexo biológico atribuído ao nascimento.

De acordo com Foucault (1988), podemos pensar a reação das(os) adolescentes perante a recusa em serem chamadas(os) pelo nome social enquanto resistência, característica inerente às relações de poder. Onde há poder, há resistência, e esta nunca está em relação de exterioridade com o poder. O poder tem caráter estritamente relacional e tais relações não podem existir se não houver pontos de resistência, que fazem o papel de adversário, de alvo, apoio e saliência, estando presentes em toda a rede de poder, não havendo, portanto, um lugar da "grande Recusa".

Mas quando Estrela chega, para os(as) profissionais, os incômodos com Joãos vão para segundo plano. Ao mesmo tempo, os últimos passam a reivindi- car mais fortemente seu reconhecimento como João, inclusive tendo havido um caso em que um João, identificando-se como sujeito de gênero masculino, solicitou transferência para uma unidade masculina. A presença de Estrela fez com que este jovem, por exemplo, encontrasse no termo "trans*" uma narrativa possível e cheia de sentido para sua experiência de gênero - 0 que não significa que todo João se designe como trans* ou deseje ser reconhecido como homem.

Há de se entender, nesse sentido, a categoria João como uma categoria êmica que toma sentidos e contornos específicos no contexto das unidades socioeducativas femininas, não sendo criadas em um vácuo, mas sim na materialidade de relações que criam determinadas condições de possibilidade de enunciar o gênero, sendo muitas vezes acionada no contexto de disputas de poder que, arraigadas na heteronormatividade, criam a necessidade de se construir narrativas de si e do gênero que possibilitem a passagem de certos desejos, afetos e possibilidades, não sendo possível presumir uma relação óbvia e necessária entre ser/ estar João no Degase e identificar-se como transexual. Neste contexto, não é simples a discussão sobre a possibilidade de Joãos ou jovens homens trans* serem transferidos para unidades masculinas, questão esta que tensiona diferentes atores, como agentes, equipe técnica e defensoria pública, num processo que certa vez foi enunciado por uma defensora pública como concorrência de direitos, em que a garantia do cumprimento da medida em unidade condizente com a identidade de gênero implicaria na impossibilidade de garantir a integridade física deste jovem uma vez que ele estivesse na unidade masculina, sendo a principal preocupação a possibilidade de estupros corretivos.

Há percepções variadas entre agentes e outros(as) profissionais tanto no que diz respeito às possibilidades de Joãos irem para unidades masculinas quanto no que diz respeito ao uso do nome social nas unidades, tendo alguns profissionais expressado que compreendem mais facilmente a questão identitária apresentada tanto por Joãos quanto por Estrela. O mesmo se dá entre as jovens: É comum que as outras internas, tanto João quanto Maria, chamem Estrela de "viado", fazendo referência a seu órgão genital e colando identidade de gênero, orientação sexual e sexo designado ao nascimento; ao mesmo tempo, foi possível ouvir relatos de que outras jovens teriam interesse e desejo por Estrela, mas tinham medo de represálias por parte das outras. As reações à Estrela e seu corpo, portanto, 
são muitas e diversas, e sua passagem pela unidade tensionou práticas, discursos, desejos, afetos e percepções a respeito dos direitos.

Estrela provocava nas pessoas o que Foucault (1988) chama de "vontade de saber", a busca de uma verdade no sexo, pois muitas dúvidas foram levantadas, em especial quanto aos critérios para se identificar uma adolescente trans*, tendo agentes socioeducativos(as) direcionado para a equipe técnica essa tarefa, acreditando que ela pudesse dispor de algum instrumental que lhes conferisse uma essência verdadeira e imutável.

Foucault (2017) ressalta que é com muita dificuldade que se admite que um indivíduo adote um sexo que não seja aquele que lhe foi biologicamente designado. Hoje, a ideia de que devemos buscar um verdadeiro sexo não foi totalmente dissipada, visto que ainda podemos encontrar, mesmo que de modo mais difuso, na psiquiatria, psicanálise, Psicologia e na opinião corrente a ideia de que há relações complexas, obscuras e essenciais entre sexo e verdade.

Assim, não conseguimos facilmente nos despir da ideia que suspeita que certos modos dissidentes de viver a sexualidade e o gênero sejam, no mínimo, "inúteis" (grifo do autor). É o que vemos no questionamento de muitos profissionais em relação ao nome social tanto de Estrela quanto dos Joãos: "por que eu tenho que chamar pelo nome social?" é uma pergunta frequente, que demonstra esse estranhamento e busca da verdade no sexo, na tentativa de adequar a uma ordem estabelecida, de que Foucault nos fala.

Vi que a determinação judicial trouxe um certo ar de respeito a isso, pois de fato a maioria dos agentes estava chamando pelo nome social, o que não acontecia quando algum João reivindicava que fosse chamado pelo nome social. $\mathrm{O}$ argumento era sempre o de que isso não estava correto, pois não estava de acordo com o seu sexo biológico. Era comum algum agente chamar pelo nome civil quando eu pedia que trouxesse uma adolescente para o meu atendimento e me referia ao seu nome social. É claro que eu insistia, e já tive alguns diálogos loucos onde usávamos nomes distintos para tratar de uma mesma pessoa (eu usando o nome social e a agente, o nome civil) (Diário de campo, 2017).

A recusa a chamar pelo nome social tensiona a relação, produzindo embates que fortalecem a lógica identitária de modo limitador, não proporcionando brechas para a criatividade. Foucault, entrevistado por Gallagher eWilson (1984), coloca a importância do respeito aos direitos do indivíduo no que diz respeito à sexualidade, em especial onde são reiteradamente desrespeitados, tal como ainda ocorre no Degase. Porém, é preciso utilizar a identidade como um primeiro passo, algo primordial para alcançarmos uma afirmação não somente enquanto identidades, mas enquanto força criativa. Uma das pistas de criatividade é a afirmação de gênero de modo distinto ao esperado socialmente, que pode ser vista como um grau de autonomia e, especificamente no sistema socioeducativo, também como indicadores de proteção e liderança.

Temos visto que intervenções profissionais que se baseiam no confronto e negação reforçam o binarismo de gênero, com seus efeitos de hierarquização e dominação do masculino sobre o feminino. No entanto, se tomarmos, a identidade como um jogo, tal como Foucault defende (Gallagher eWilson, 1984), para fazer novas interações, criar laços e se diferenciar, é possível potencializar as brechas que tal afirmação identitária nos traz para problematizarmos as construções de gênero que ainda vigoram em nossa sociedade.

As identidades trans* abrem um debate sobre a essencialidade do sujeito. Garcia (2011) discute que o uso essencialista da identidade apaga a potência política estratégica e transformadora das críticas trazidas pelo movimento LGBT. Ao extrapolar o âmbito político das lutas pela garantia de direitos, se tornando algo central na definição da existência, acaba por entrar no jogo do controle biopolítico dos corpos, como a patologização das identidades trans* (Garcia, 2011).

Nesse sentido, concordamos com as reflexões de Berenice Bento (Dias, 2014), radicalizando o debate em torno das construções de gênero. A autora afirma que a produção de sujeito no mundo se constitui num rígido protocolo de gênero e sexualidade que produz as identidades de homem e mulher com base na biologia, construindo identidades de gênero de modo vinculado aos atributos sexuais. O gênero, para ela, é um elemento fundante da política de Estado, pois "os temas relacionados às populações são sempre tratados em função da ideia do masculino/homem e feminino/mulher" (p. 486).

Aproximando-se de Scott (1989), a autora vai pensar na serventia da categoria gênero, quando afirma que o mesmo faz parte de relações de poder, sendo operador político que cumpre o mesmo papel 
da noção de raça: "produção incessante de hierarquias assimétricas e desiguais" (Dias, 2014, p. 484). Entendendo o gênero enquanto performance, tal como Butler (2003), e não como algo imutável e definidor do sujeito, Bento (2014) defende a luta pela abolição do gênero, no sentido de esvaziar o seu caráter de opressão, entendendo que tal luta "dialoga intensamente com a experiência histórica da luta pelo fim do racismo e da escravidão" (p. 483), pois se defendia que a cor da pele era preditor dos modos de agir e pensar, colocando os negros em posição de inferioridade e submissão em relação aos brancos.

A luta pelo fim do gênero, no entanto, não deve operar como um dispositivo de invisibilização das violências produzidas pela heteronormatividade e pela cisgeneridade como modelo, e nem ignorar a relevância de reivindicações como as de Estrela, que se afirma como sujeito de direitos a partir de sua afirmação identitária como trans*. Em um contexto de binarismo de gênero, é pertinente que sujeitos que não se encaixam nas prescrições de gênero da heteronorma reivindiquem o reconhecimento de suas identidades ainda que isso signifique, de algum modo, a manutenção desses binarismos.

Ao falar em abolição de gênero, a autora pensa em afirmar a fluidez da experiência humana, combatendo as supostas determinações biológicas para explicação das subjetividades e desejos, sem ignorar as possibilidades de se fixar ocasionalmente através de identidades mais bem estabelecidas. A abolição de gênero, neste sentido, parte das inúmeras possibilidades de viver as transexualidades, trazendo imediatamente deslocamentos nas noções normativas de masculinidade e feminilidade (Dias, 2014).

\section{Revista íntima: violação em nome da segurança}

A perspectiva binária dos gêneros perpassa inúmeros procedimentos no Degase, devendo ser destacado o procedimento de revista íntima, naturalizado enquanto esquema necessário para a garantia da segurança. Trata-se de um momento delicado tanto para $\mathrm{a}(\mathrm{o})$ jovem quanto para o(a) agente que realiza a revista, pois é necessário que a(o) adolescente retire suas roupas para que o(a) profissional verifique se ela(e) esconde alguma droga ou objeto perfurocortante em suas partes íntimas. Para as meninas cis, há ainda o constrangimento de se agachar, a fim de provar que nada escondem dentro de suas vaginas.
Com a ida de Estrela para a unidade feminina, tal procedimento passou a ser alvo de discussão dos profissionais e, consequentemente, do GT de Diversidade Sexual. Percebemos que se tratava de um instituído não previsto em nenhuma normativa legal, pois até mesmo o Regimento Interno do Degase ainda estava em construção. De todo o modo, a prática seguia os moldes da Polícia Militar: homem revista homem e mulher revista mulher. Porém, o critério balizador para definir homem e mulher era o sexo biológico, e não o gênero, haja vista que um dos primeiros pontos levantados era quem revistaria Estrela. Na dita impossibilidade de abrir mão do procedimento, a situação tornou-se um impasse.

O constrangimento por parte das agentes femininas, nesse momento apoiadas pelos agentes masculinos, emergiu como um importante entrave para realizar as revistas, visto que Estrela tinha o órgão genital masculino. Porém, como nenhuma instituição se resume ao instituído, forças instituintes movimentaram a questão do constrangimento, configurando um campo em que não há consenso até mesmo entre o corpo de agentes:

As agentes que se sentiam incomodadas traziam aspectos relativos a uma moralidade, de serem mulheres e terem que revistar um "homem". No entanto, outras agentes se mostraram muito disponíveis à revista e a compreender a questão da transexualidade, não se sentindo tão afetadas pelas questões morais de diferença de sexo biológico na revista. Uma delas, inclusive, disse que revistou tranquilamente a adolescente, que se mostrou respeitosa enquanto era revistada, ressaltando que "aqui é tudo tão louco que nada me assusta mais" (sic); tal fala foi corroborada por outra agente, que expressou certo incômodo com o incômodo de alguns profissionais quanto a isso. Tais falas circularam pelos/as agentes que estavam mais abertos à questão, expressando a compreensão de que são servidores e que precisam executar as leis e garantir os devidos direitos, independente de concordar/compreender ou não com a questão da transexualidade (Diário de campo, 2016).

Um elemento que frequentemente surgia nas falas de agentes dizia respeito ao medo de serem responsabilizados no cumprimento de suas funções, evi- 
denciando mais uma vez como o medo é importante operador político das práticas e discursos no Degase. Este medo era reforçado pelo fato de não haver dispositivos legais que regulamentassem efetivamente a prática da revista íntima, o que aponta para uma questão pertinente que é a relação de incerteza que estes profissionais têm com suas práticas, estando inseridos em um contexto em que, de maneira ampla, educação e punição se confundem nas práticas cotidianas e nas normativas. A questão é pertinente, mas insuficiente para compreender as dinâmicas que tornavam a revista íntima um tema delicado quando se tratava de Estrela - afinal, antes de sua chegada à unidade não havia, da mesma forma, normativas específicas a respeito da regulamentação desta prática, e nem por isso os(as) agentes sentiam-se desconfortáveis em praticá-la.

\section{O atendimento ao público LGBT no Regimento Interno: um novo instituído e a busca por novos movimentos instituintes}

Com a publicação do Regimento Interno do Degase, a seção sobre atendimento a jovens LGBT nas unidades de internação e semiliberdade trazem novos ares para a discussão sobre a revista íntima e o nome social. Fruto do longo e coletivo processo de trabalho do GT diversidade sexual e de gênero, a seção traz materialidade a direitos desses jovens, deixando claro, em seu art. 43, que "o acautelamento e o cumprimento da medida socioeducativa se dará nos Centros de Atendimento Socioeducativo e levará em conta o interesse do(a) jovem atendido(a), em acordo com a identidade de gênero, salvaguardando sua integridade física e mental". Além disso, expressa regulamentações quanto ao uso do nome social e à revista:

Art. 42, § $3^{\circ}$ - O nome social deverá ser utilizado pelos/as socioeducadores(as) no chamamento dos(das) socioeducandos(as) durante todo o processo de cumprimento de medida no Degase, independente do Centro de Atendimento de cumprimento da medida socioeducativa, obser- vando o preconizado no caput acerca da capacidade civil dos(as) adolescentes.

Art. 45 - A revista do(a) adolescente transexual ou travesti deverá ocorrer individualmente em ambiente onde não se imponha exposição corporal vexatória, em ambiente reservado e que assegure a privacidade.

$\$ 1^{\circ}$ - Caberá ao Centro de Atendimento Socioeducativo disponibilizar um agente de segurança socioeducativo masculino e um feminino, para realização da revista, com a anuência dos servidores, sendo facultado(a) ao(à) socioeducando(a) a escolha de quem realizará o procedimento.

No entanto, sabemos que a regulamentação não extingue os desafios cotidianos da garantir direitos, que insere numa constante trama de disputas e tensões, exigindo, portanto, constante abertura para a criação de novos instituintes e movimentos nesse jogo que ora garante, ora viola direitos. A passagem de Estrela pelo Degase foi marcada por dificuldades e violências sofridas por ela; ainda assim, o acontecimento Estrela permitiu uma série de movimentos que se desdobraram em ações e estratégias que tornaram possível, por exemplo, que outras jovens trans* fossem internadas diretamente na unidade feminina, sem antes passarem por unidades de internação masculinas - o que evidentemente não resolve a questão, mas lança novas luzes para as velhas e novas questões que emergem quando o Degase se vê atravessado por vidas e corpos trans*.

Se, por um lado, Estrela lançou luz sobre os desafios e possibilidades da atuação no cotidiano em unidades de internação do sistema socioeducativo, por outro o próprio fato de ela passar pelo sistema aponta para outras tramas que, através de processos de violência, marginalização e violação de direitos, fizeram com que o Degase fizesse parte de sua trajetória de vida. Quanto a isso, há ainda muito a se discutir sobre os processos de criminalização e incriminação que, cada vez mais, têm privado de liberdade jovens mulheres travestis e transexuais.

\section{Referências}

Barros, A., \& Julião, E. (2015). Reflexões sobre orientação sexual e identidade de gênero no sistema socioeducativo do Rio de Janeiro. In C. L. S. Mendes, E. F. Julião, \& J. F. S. Abdalla (Orgs.), Diversidade, violência e direitos humanos (pp. 117-132). Rio de Janeiro, RJ: Degase. 
Butler, J. (2003). Problemas de gênero: Feminismo e subversão da identidade. Rio de Janeiro, RJ: Civilização Brasileira.

Carvalho, S. (2012). Sobre as possibilidades de uma criminologia queer. Sistema Penal \& Violência, 4(2), 152-168.

D’Angelo, L. B. (2017) Entre "sujeita-mulher" e "mulher de bandido": Produções de feminilidades em contexto de privação de liberdade (Dissertação mestrado). Instituto de Psicologia, Universidade do Estado do Rio de Janeiro, Rio de Janeiro, RJ, Brasil.

D’Angelo, L. B., \& Garay Hernández, J. (2017). Sexualidade, um direito (secundário)? Atravessamentos entre sexualidade, socioeducação e punição. Plural: Revista de Ciências Sociais, 24(1), 78-104. https://doi.org/10.11606/ issn.2176-8099.pcso.2017.125958

Decreto No 8.727, de 28 de abril de 2016. Dispõe sobre o uso do nome social e o reconhecimento da identidade de gênero de pessoas travestis e transexuais no âmbito da administração pública federal direta, autárquica e fundacional. Diário Oficial da União. Recuperado de http://www.planalto.gov.br/ccivil_03/_ato2015-2018/2016/ decreto/D8727.htm

Decreto No 43.065 de 8 de Julho de 2011. Dispõe sobre o direito ao uso do nome social por travestis e transexuais na administração direta e indireta do estado do Rio de Janeiro e dá outras providências. Diário Oficial da União. Recuperado de https://www.saude.rj.gov.br/comum/code/MostrarArquivo.php?C=NzIlMw\%2C\%2C

Decreto No 46.525, de 13 de dezembro de 2018. Aprova o regimento interno do departamento geral de ações socioeducativas. Diário Oficial do Estado do Rio de Janeiro.

Dias, D. M. (2014). Brincar de gênero, uma conversa com Berenice Bento. Cadernos Pagu, (43), 475-497. https://doi. org/10.1590/0104-8333201400430475

Foucault, M. (2017) O verdadeiro sexo. In M. Foucault, Ditos e escritos, volume V: Ética, sexualidade, política (3a ed., pp. 81-90). Rio de Janeiro, RJ: Forense Universitária.

Foucault, M. (1987). Vigiar e punir (22a ed.). Petrópolis, RJ: Vozes.

Foucault, M. (1988). História da sexualidade 1: A vontade de saber. Rio de Janeiro, RJ: Graal.

Freire, L. (2013). A ciência em ação de Bruno Latour. IHU On-Line, 13(416).

Gallagher, B., \&Wilson, A. (1984). Michel Foucault, uma entrevista: Sexo, poder e política de identidade. The Advocate, (400), 26-30.

Garcia, A. M. (2011). O que sou? Do que gosto? Identidades em análise nas lutas em defesa da diversidade sexual (Dissertação de mestrado). Instituto de Ciências Humanas e Filosofia, Universidade Federal Fluminense, Niterói, RJ, Brasil.

Lei No 8.069, de 13 de julho de 1990. Dispõe sobre o estatuto da criança e do adolescente e dá outras providências. Diário Oficial da União. Recuperado de http:/ /www.planalto.gov.br/ccivil_03/leis/l8069.htm

Lourau, R. (1993). Terceiro encontro: 28.04.93. In R. Lourau, Análise institucional e práticas de pesquisa (pp. 49-74). Rio de Janeiro, RJ: Universidade do Estado do Rio de Janeiro.

Passos, E., \& Eirado, A. (2014). Cartografia como dissolução do ponto de vista do observador. In L. Escóssia, V. Kastrup, \& E. Passos, Pistas do método da cartografia: Pesquisa-intervenção e produção de subjetividade (pp. 109-129). Porto Alegre, RS: Sulina.

Silva, J., Sereno, G., \& Gonçalves, H. (2014). A visita íntima de adolescentes no sistema socioeducativo como dispositivo de enunciação de questões relativas às sexualidades. In E. Julião, J. Abdalla, \& S. Vergílio (Orgs.), Delinquência juvenil, políticas públicas e direitos humanos (pp. 131-151). Rio de Janeiro, RJ: Novo Degase.

\section{Aline Monteiro Garcia}

Professora na Universidade Estácio de Sá, Rio de Janeiro - RJ. Brasil. Psicóloga no Departamento Geral de Ações Socioeducativas do Rio de Janeiro (Degase-RJ), Rio de Janeiro - RJ. Brasil.

E-mail: alinegarcia.psic@gmail.com

(iD) https://orcid.org/0000-0002-6224-6378 


\section{Luisa Bertrami D’Angelo}

Psicóloga. Doutoranda em Psicologia Social pela Universidade do Estado do Rio de Janeiro (UERJ), Rio de Janeiro

- RJ. Brasil.

E-mail: luisabertrami@gmail.com

iD https:// orcid.org/0000-0001-5724-3511

Endereço para envio de correspondência:

Rua 24 de maio 859 bloco 2 apt 711 - Engenho Novo, Rio de Janeiro, Brasil.

Recebido 26/09/2019

Aceito 04/ 10/2019

Received 09/26/2019

Approved 10/04/2019

Recibido 26/09/2019

Aceptado 04/10/2019

Como citar: Garcia, A.M., \& D’Angelo, L.B. (2019). Corpos trans* na medida socioeducativa de internação: desestabilizando práticas e produzindo novidades. Psicologia: Ciência e Profissão, 39 (n.spe 3), $242-256$. https://doi.org/10.1590/1982-3703003229281

How to cite: Garcia, A.M., \& D’Angelo, L.B. (2019). Trans* bodies in the juvenile detention centers: destabilizing practices and producing novelties. Psicologia: Ciência e Profissão, 39 (n.spe 3), 242-256. https://doi.org/10.1590/1982-3703003229281

Cómo citar: Garcia, A.M., \& D’Angelo, L.B. (2019). Los cuerpos trans* en centros de encarcelamiento juvenil: prácticas desestabilizadoras y producción de novedades. Psicologia: Ciência e Profissão, 39 (n.spe 3), $242-256$. https://doi.org/10.1590/1982-3703003229281 